\begin{tabular}{|c|l|}
\hline Title & E-waste Management in Japan: a focus on A ppliance Recycling \\
\hline Author(s) & Yoshida, Fumikazu; Y oshida, Haruyo \\
\hline Citation & Eighth International Conference on Waste Management and Technology, 23-25 October 2013,Shanghai China \\
\hline Issue Date & 201310 \\
\hline Doc URL & http://hdl.handle.net/2115/54736 \\
\hline Type & proceedings (author version) \\
\hline File Information & ICWMT 8.pdf \\
\hline
\end{tabular}

Instructions for use 
Recommended Excellent papers of the 8th International Conference on Waste Management and Technology 2013.10.-23-25 Shanhai 144-147

\title{
E-waste Management in Japan: a focus on Appliance Recycling
}

\author{
Fumikazu Yoshida, a, Haruyo Yoshida'b \\ ${ }^{1}$ Hokkaido University, Graduate School of Economics
}

Sapporo 060-0809 Japan

${ }^{2}$ Sapporo University, Sapporo 062-8520 Japan

ayoshida@econ.hokudai.ac.jp, ${ }^{b}$ hry@song.ocn.ne.jp

Keywords: e-waste, house appliances, recycling, TV sets, air conditioners

\begin{abstract}
As 10 years have passed since the Japanese home electrical appliance recycling system came into operation, the results of the system have become clearer, and it is therefore time for us to analyze and evaluate its performance in terms of both the environment and the economy. The system covers 4 specified house appliances, and although roughly $2 / 3$ of these discarded appliances are collected and recycled formally by the manufactures, the greater part of the remaining $1 / 3$ is exported as used items or scrap. Consequently, the government has issued guidelines for the reuse and recycling as countermeasures against illegal dumping and to regulate the export of e-scrap.
\end{abstract}

\section{Introduction}

Japan initiated the home electrical appliance recycling system in 2001 to provide for the proper disposal of e-waste and the more effective use of resources. Under this law retailers must take back, and manufactures (including importers) must recycle four specified types of consumer appliance: air conditioners, TV sets, refrigerators, and washing machines. Consumers (waste generators) are required to pay a fee for collection, transport and recycling when discarding any one of these four types. Now that 10 years have passed, the results of the home electrical appliance-recycling program have become clearer, and we would therefore like to analyze and evaluate the system performance in terms of both its environmental and economic aspects.

\section{The Content of Appliance Recycling}

What we call the 'material cycle' is designed to include not only the recycling of televisions, refrigerators, air conditioners, washing machines, and other consumer appliances but also the recovery of such materials as the lead in TV picture tubes and the heavy metals in electronic circuit boards, the refrigerants in air conditioners, and the plasticizers in plastics, while the recovery of ferrous and nonferrous metals is intended to conserve and make more effective use of such resources. Each year the Japanese discard over 70,000 tons of the so-called "four types" of appliance.

\section{System Features of Appliance Recycling}

The Japanese scheme requires consumers to pay a recycling fee of 1500-4800 JPY at the time of disposal of any one of the 4 designated large-size electrical appliances. Current regulations require retailers to take back goods that they have sold, while manufactures are required to recycle them. The system has achieved a relatively high collection and recycling rate: in 2011, this came to about 2/3 of all discarded units (20 million units/32 million units). The success of the current system depends upon (1) the clear responsibility of each actor, (2) the limitation of the system to four items only (TV sets, Air Conditioners, Refrigerators, Washing machines), (3) the Japanese trade-in system of old for new, (4) government investment in the recycling facilities with a subsidy of about $50 \%$ (devoted to building and infrastructure for green business); and (5), after 2010, an “Eco-Point” subsidy for the replacement and disposal of energy saving equipment (since consumers do not pay any recycling fee). 


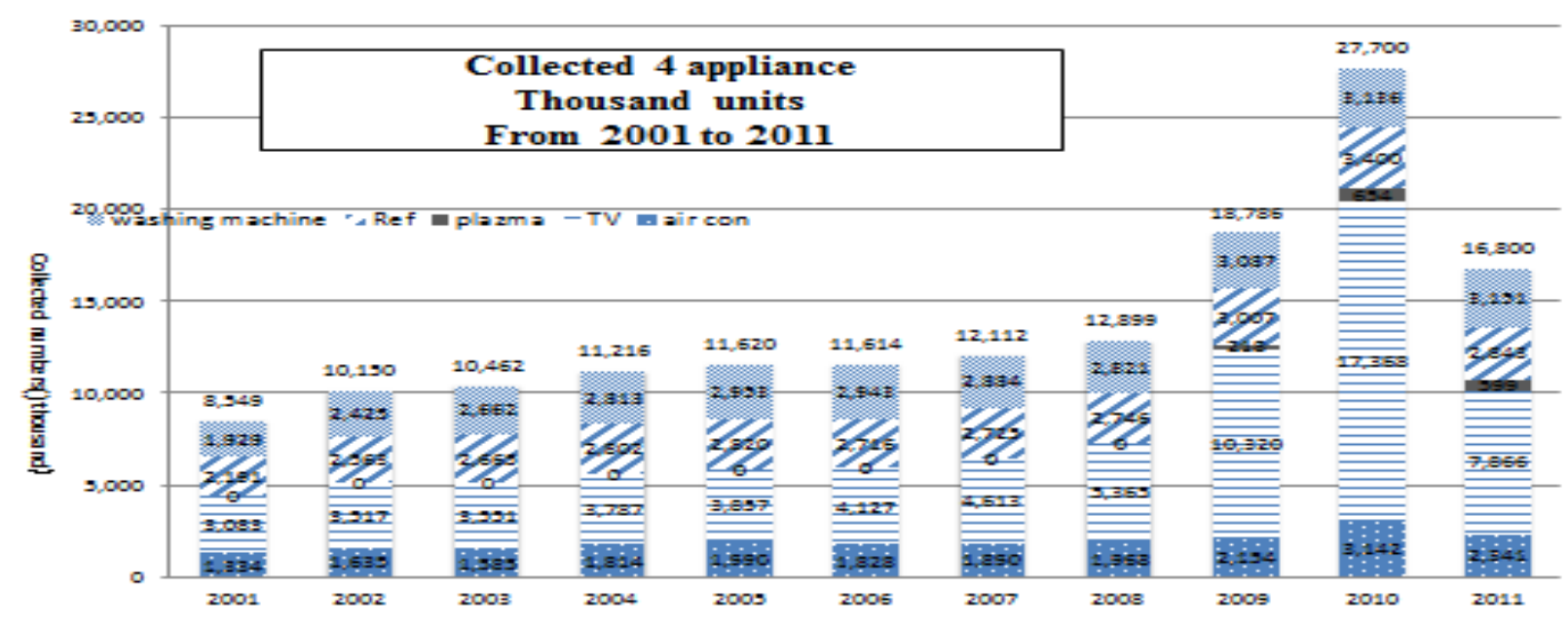

Figure 1 Collected 4 Appliance from 2001 to 2011 for Recycling

\section{Overview of the Performance}

In 2010, the number of recycled appliances reached 27 million units; most notably(Fig.1), the recovery of used TV sets had reached 17 million units. The recycling rate of recovered appliances is now close to $80-90 \%$. In 2010, the amount of recovered CFC came to about 1870 ton(s). Estimates indicate that about 160 thousand units per year are dumped illegally.

The reasons why there has been so much recycling of TV sets are clear: (1)Since the Japanese Broadcasting System was due to complete a change from analogue to digital broadcasting by the end of July 2011, analogue sets are now obsolete and their disposal has become a social problem. (2) Once the temporary "Special Demand" collection of analogue sets has been completed, however, this problem will become less severe. (3) Yet no one knows how to deal with used CRT (hazardous cullet with $\mathrm{Pb})$ ? There are no recycling facilities in Japan and those in other countries are decreasing.

At the same time, the export of used TVs is increasing (source: Japanese Trade Statistics[1], HS code 8528.72.990): In 2008: of the 2.24 million units exported, 0.77 million went to Vietnam, 0.56 million to Macao, and 0.46 million to the Philippines; In 2009: of the 2.29 million units exported, 0.79 million went to Vietnam, 0.78 million to Macao, and 0.48 million to the Philippines; In 2010: of the 2.53 million units exported, 1.08 million went to Vietnam, 0.68 million to Macao, and 0.56 million to the Philippines; In 2011: of the 2.82 million units exported, 1.63 million went to Vietnam, 0.25 million to Macao, and 0.58 million to the Philippines; In 2012: of the 1.31 million units exported, 0.45 million went to Vietnam, 0.10 million to Macao, and t 0.46 million to the Philippines(Tab.1).

The export of used TV sets peaked in 2011 because completion of the "Special Demand" program set up to deal with the transfer to digital TV meant that analogue sets had by then become obsolete and had been mostly traded in. At the same time, figures available for the export of used PC monitors (HS code: 8528.51.900) show that 1.25 million units of recovered monitors went to Vietnam in 2011 and 0.64 million units in 2012, while 0.64 million units were exported to Hong Kong in 2011 and 1.58 million in 2012. The domestic demand for used TV sets in the Philippines seems equivalent to the quantity exported to that country, but the domestic demand for used TV sets and PC monitors in Vietnam, Macao, and Hong Kong appears to be less than the quantity exported, which suggests that some used TV sets and computer monitors are being sent to third countries[4]. 
Export of Used Appliance from Japan

(source: Japan Trade Statistics)

\begin{tabular}{|l|c|c|c|c|c|}
\hline HS Code & 2008 & 2009 & 2010 & 2011 & 2012 \\
\hline $\begin{array}{l}\text { AlR CON } \\
(841510900)\end{array}$ & 59301 & 29549 & 21429 & 22126 & 32814 \\
\hline $\begin{array}{l}\text { TV } \\
(852872990)\end{array}$ & 2299766 & 2309837 & 2569068 & 2829966 & 1315657 \\
\hline $\begin{array}{l}\text { REF } \\
\text { (841810900) }\end{array}$ & 114906 & 70532 & 47405 & 1384626 & 409197 \\
\hline $\begin{array}{l}\text { WASHING } \\
\text { Machine } \\
\text { (845011900) }\end{array}$ & 22992 & 5111 & 6075 & 3981 & 5221 \\
\hline
\end{tabular}

\section{The export of e-waste problems}

According to the Japanese government's MOE flow estimation of the four appliances in 2011[3], about 31.3 million units of all four types of appliance were discarded, of which about 3.4 million units were kept in store. The formal tally of recycled appliances numbered about 19.5 million units, which amounts to roughly $2 / 3$ of all discarded units. Of the remaining $1 / 3$, estimates indicate that 3.62 million units were exported as scrap, 2.94 million were exported for further use, 2.15 million were reserved for domestic reuse, and 0.96 million went as domestic scrap. It is noteworthy that estimates for TV sets exported as scrap amount to as many as 2.21 million units, while air conditioners and refrigerators come respectively to 0.77 million and 0.21 million[Fig.2].

Detailed estimation of used TV sets shows that in 2011, 17.6 million units were discarded, of which 9.2 million were collected by retailers and 10.6 million units were recycled by manufactures. The other route for the gathering of discarded units is the one followed by civic collectors, who yearly pick up 5 million units, while the reuse shops collect 0.87 units. Analysis of the final destination of used TVs estimate that 10.6 million units are recycled by manufactures, 1.62 million are reused domestically, 2.72 million are exported, 0.51 million go to domestic scrap, while 2.20 million sets are exported as scrap. It appears that the total of used TV and TV sets exported as scrap amounts to 5 million units, which is about half the number of units recycled domestically.

The 2011 figures for used air conditioners indicate that a total of 3.99 million units were discarded, of which 2.15 million were collected by retailers and 2.37 million were recycled by manufacturers. Of the other 1.62 million units, it is estimated that domestic reuse accounts for 0.66 million units, domestic scrap accounts for 0.16 million, while 30 thousand units are exported for reuse and 0.77 million are exported as scrap. We therefore conclude that in case of TV sets and air conditioners, the greater part of other than that attributed to formal domestic recycling is the export of the units either for reuse or as scrap (about 1/2 to 1/3 of what is recycled formally).

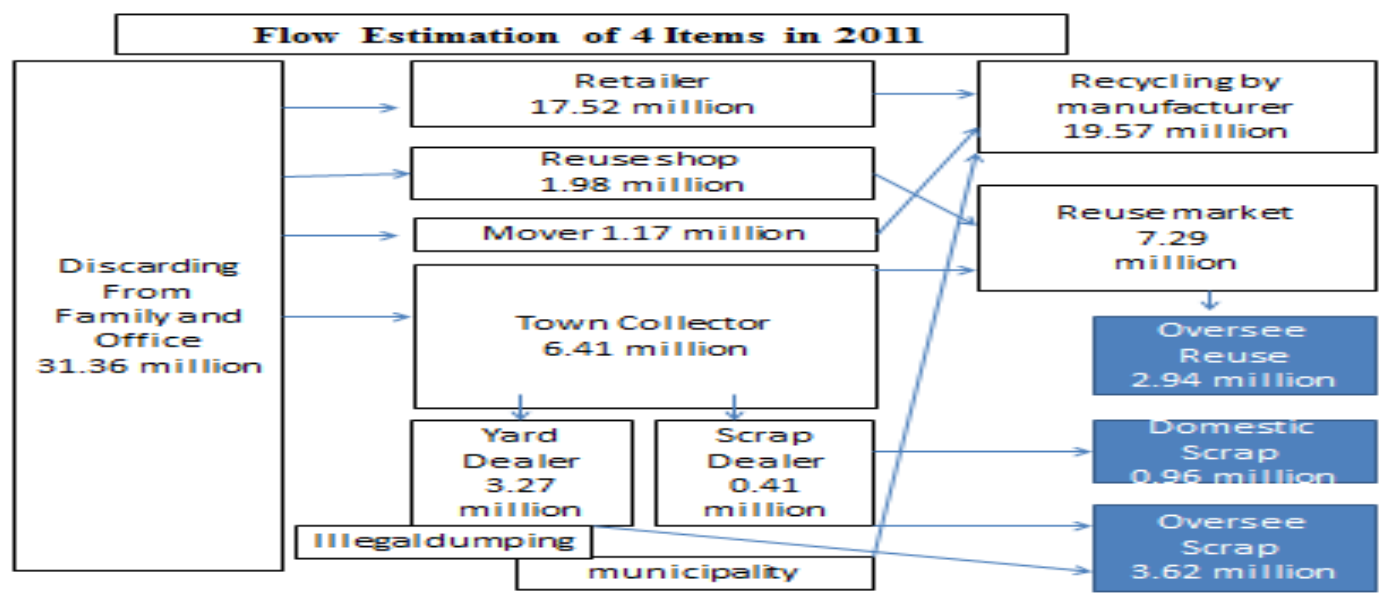

Figure 2 Flow estimation of 4 Items in 2011[3] 


\section{The agenda for the furtherance of the appliance recycling system}

In 2008, the regulators produced an evaluation report on the appliance recycling system that set out an agenda of five points that need to be addressed.

(1) The transparency of the recycling cost, reducing the recycling cost

Since consumers have to pay the recycling cost, these costs have to be made public. According to the available data, the total recycling cost in recent years exceeds the revenue generated by recycling by about 1300-1600 million JPY, a share of the costs that manufactures have to recover. At the same time the cost of recycling air conditioners has been reduced from 3675 JPY in 2001 to 1575 JPY in 2013, and for both small size TVs and refrigerators the recycling cost was reduced respectively from 2835JPY to 1785 JPY and from 4830JPY to $3780 \mathrm{JPY}$. The cost of recycling washing machines (2520JPY), however, did not change.

(2) Guidelines for reuse and recycling

In 2012, the regulators issued two guidelines for reuse and recycling: one designated checking the year of production and the other the appearance and suitability of units for reuse, while a common deposit for recycling of units taken back by retailers has recently become available.

(3) Countermeasures against illegal dumping

As a countermeasure against illegal dumping, the manufactures have agreed to subsidize municipalities from 2009 to 2014.

(4) Regulations for the export of e-scrap

Since town collectors are picking up used house appliances without levying a recycling cost, this leads to the export of scrap metals or used TV sets and air conditioners. Therefore the regulator has issued a guideline to check which units are still usable and which are simply pure waste. And as a means to stop the illegal export of used appliances, Japan's MOE has issued guidelines based on the Basel Law and waste management to legislate for the export of used TV sets and is now considering similar guidelines for other electrical and electronics goods. MOE is also reviewing methods for analyzing metal scrap that has been mixed in with used electrical and electronics goods.

(5) Coordination between small electrical and electronics appliance recycling programs

This year the regulators have inaugurated a system for recycling small electrical and electronics appliances[2]. Since this system is based on voluntary efforts, consumers do not have to pay the recycling cost, and coordination between the new system and the 4 house appliances recycling system therefore becomes necessary.

\section{Summary}

The Japanese appliance recycling system has achieved technical and economical equilibrium by sharing the cost between consumers and manufactures. Although roughly $2 / 3$ of all discarded house appliances of the 4 designated types are collected and recycled formally by the manufactures, the greater part of what remains is exported as used goods or scrap: this amounts to about 1/2 to $1 / 3$ of what is recycled formally. For these reasons, the regulators have issued the guidelines for reuse and recycling, as well as instituting countermeasures against illegal dumping and issuing regulations for the export of e-scrap. Still on Japan's agenda for electrical and electronics appliance recycling is further consideration of the transparency of the recycling cost, along with a reduction in the cost of recycling and more effective coordination with the recycling of small electrical and electronics appliances.

\section{References}

[1] MOF (Ministry of the Finance), Japan Trade Statistics of Japan, (2012).

[2] MOE, Japan, The law for recycling of used small electronics,(2012).

[3] Joint Meeting of the Industrial Structure Council, Subcommittee on Waste and Recycling, Electrical and Electronic Equipment Working Group, and Central Environment Council, Waste and Recycling Committee, Subcommittee for Assessing the Household Appliance Recycling System (2013) Estimation of Flow of WEEE in Japan,(2013).

[4] A. Terazono et al, E-waste treatment technology and its improvement in Asia, NIES(2012). 